\section{Estado de Bem-Estar Social e Democracia}

The Social Welfare State and Democracy

Nilson do Rosário Costa ${ }^{1}$

${ }^{1}$ Departamento de Ciências Sociais Escola Nacional de Saúde Pública, Fiocruz. Rio de Janeiro RJ Brasil.

O artigo Welfare State Resiste? Desenvolvimentos recentes do estado social nos países da OCDE de Kerstenetzky e Guedes ${ }^{1}$ oferece uma desafiadora contribuição à compreensão do desenvolvimento do Estado de Bem-Estar Social nas últimas quatro décadas. A despeito de não tratar das alterações nas regras de elegibilidade, no tamanho dos benefícios e na densidade da provisão, o artigo apresenta e analisa um conjunto valioso de indicadores de gastos sociais.

Utilizando a tipologia dos regimes de Welfare State de Esping-Andersen ${ }^{2}$, as autoras demonstram que ocorreu no período 1990-2016 a expansão generalizada dos gastos sociais nos diferentes grupos de países; a corrida para cima, com os países retardatários diminuindo a distância dos líderes e a permanência na liderança na proteção social dos países nórdicos. Desse modo, o Estado de Bem-Estar Social não encolheu, ao contrário dilatou-se, pelo aumento da tributação, permanência da progressividade e orientação redistributiva ${ }^{1}$.

$\mathrm{O}$ artigo contesta, assim, os prognósticos das ciências sociais sobre o irremediável declínio do Estado de Bem-Estar nas sociedades capitalistas. A partir dessas previsões, tornou-se corriqueiro associar as mudanças no regime de acumulação, a ofensiva neoliberal e a globalização à completa reorganização do Estado de Bem-Estar social, desconsiderando as idiossincrasias nacionais. Em 1997, Fiori, por exemplo, afirmou que "ocorreu uma confluência e sucessão de acontecimentos (...) que acabaram abalando, de forma aparentemente definitiva, as bases em que se sustentavam as pilastras do Welfare State dos anos 50/60"3.

Dois comentários ao excelente artigo: primeiro, o diálogo com a contribuição Pierson ao tema da crise da proteção social na Inglaterra e Estados Unidos, especialmente no livro Dismantling de
Welfare State ${ }^{4}$, poderia ser mais extenso. O autor trouxe para a cena a mediação de variáveis institucionais e de dependência de trajetória para a análise dos processos políticos contemporâneos, indicando um marco teórico para a compreensão das iniciativas de demolição do Estado de Bem -Estar Social. Com base no neoinstitucionalismo histórico, Pierson chamou a atenção para os vetos à agenda conservadora nas democracias partidárias competitivas, particularmente pelas preocupações eleitorais da classe política. O autor identificou também que o efeito das reformas estruturais foi mais contundente nos programas focalizados nos pobres do que nas políticas sociais universalistas. Estas últimas seriam mais resilientes em função da advocacia de defesa dos beneficiários, usuários e burocracia pública.

Segundo, a classificação em regimes Social Democrata, Conservador e Liberal proposta por Esping-Andersen é muito apropriada para a descrição dos Estados de Bem-Estar social, mesmo que sujeita à correção ${ }^{5}$. Porém, a aplicação na análise de políticas sociais setoriais exige certa calibração. No setor saúde, por exemplo, a tipificação da Inglaterra como um regime liberal não é empiricamente aceitável. Naquele país ocorreu o desenvolvimento pioneiro do modelo de Sistema Nacional de Saúde (SNS) universal e financiado por fontes fiscais. O SNS inglês definiu, paradoxalmente, um regime institucional-redistributivo na assistência à saúde em uma sociedade com um regime liberal-meritocrático de proteção social.

\section{Referências}

1. Kerstenetzky CL, Guedes GP. O Welfare State Resiste? Desenvolvimentos Recentes do Estado Social nos Países da OCDE. Cien Saude Colet 2018; 23(7):2095-2106.

2. Esping-Andersen G. The Three Worlds of Welfare Capitalism. New Jersey: Princeton University Press; 1990.

3. Fiori JL. O Estado de Bem-Estar Social: Padrões e Crises. Physis 1997; 7(2):147.

4. Pierson P. Dismantling the Welfare State? Reagan, Thatcher, and the Politics of Retrenchment. Cambridge: Cambridge University Press; 1995.

5. Ferrera M. The 'Southern' Model of Welfare in Social Europe. J Eur Soc Policy 1996; 6(1):17-37. 
